\title{
Influence of Ventilation on Gas Emission in No pillar Mining
}

\author{
Weidong Lu ${ }^{1, a}$, Bin Yin ${ }^{1, b}$ \\ 1 Department of Safety Engineering, Xinjiang Institute of Engineering, Urumqi830000, China \\ aluweidong1990@126.com, ${ }^{b}$ Ingdyinbin@163.com
}

Keywords: No pillar; Ventilation; Gas emission.

Abstract: The emergence of pillar-free pillar technology instead of coal pillar technology has raised new requirements for safe production of coal mine. Based on the analysis of gas source, the effects of total pressure change, air flow and main fan stop on gas emission were expounded respectively. At the same time, a concrete analysis was made for the non - pillar mining. It was pointed out that air leakage is the influential factor of gas emission of the key factors.

\section{Introduction}

Coal pillar mining is not only a waste of coal resources, and coal pillars left in the mined-out area has also brought the security risks of coal spontaneous combustion. No coal pillar mining can reduce roadway coal, fundamentally eliminate the material base of coal spontaneous combustion, but also eliminates the hidden danger of coal spontaneous combustion ${ }^{[1-2]}$.In order to solve the non-pillar mining technology of high methane and spontaneous combustion coal seam, many mining areas have studied the air flow and gas distribution law of coal mine, combined with the actual production, in the experimental and the theoretical analysis, And the safety technical measures for the mining of high gas seam without pillar are worked out ${ }^{[2-3]}$.

\section{No pillar Mining}

Practice has proved that no pillar roadway protection technology is one of the effective measures to rationally develop and utilize coal resources, improve recovery rate, reduce tunneling rate, reduce roadway maintenance costs, improve technical and economic benefits, is an important reform in the mining process. Coal pillar-free mining is generally divided into drive along the roadway and lane along the road.

Driving along the road, that is, along the mining face of the mined-out area edge of the roadway. This method makes use of the edge pressure of mined - out area to excavate along the edge of goaf where the overburden rock layer has been stabilized, which is beneficial to the maintenance of the roadway during tunneling and production. Although not reducing the number of roadways along the roadway, but not leaving or leaving coal pillars, reducing the loss of coal, reducing the roadway between the section of the roadway, roadway support requirements are not too strict, easy to promote.

Lane along the road is generally applicable to thin and medium-thickness coal seam with gentle slope and inclined thickness below $2 \mathrm{~m}$. There are three types of roadway layout along goaf roadway: advance gob-side entry retaining, retrogressive gob-side entry retaining and reciprocating gob-side entry retaining. Progressive gob-side entry: face forward mining, leaving along the goaf along the roadway. Retreated roadway along goaf, first excavated section of the roadway to the mining area boundaries, mining face after the retreat and then leave the roadway along the air as the next section of the return airway. This way to overcome the forward-style recovery in front of the coal seam is unknown and stay alley face coal mining and other shortcomings, but to increase the roadway excavation workload.

\section{Division of gas source}

To study the gas emission, the underground gas emission is divided into direct source gas and indirect source gas. The so-called direct source gas, is the coal (rock) body of the adsorption of gas, due to the 
impact of mining work adsorption gas analysis becomes free gas, along the coal (rock) body of their own gaps or cracks in flow understand, flocked to the roadway or mining space, Mixed with the wind quickly after being taken away all the gas Mines. Obviously, coal mining (mining) face and the ventilation of the coal (rock) wall and broken coal in the gas released, mostly belong to this type. Indirect source gas, that is, coal (rock) of the adsorption of gas, due to the impact of mining work after the desorption into the free gas, along the coal (rock) body of their own pores or cracks flow into the roadway or goaf, Difficult to mix with the wind quickly mixed, but the accumulation, or convection diffusion in the form of migration to the nearby roadway, or by underground changes in atmospheric conditions and the flow of gas to the nearby roadway. This type of gas emission in the old tunnel and in the goaf without ventilation is mostly of this type. Obviously, it is not equal to the size of the coal (rock) cracks that part of the gas emission ${ }^{[4]}$. From the above we can see that mine air flow in a moment to carry the amount of gas is not equal to mine coal (rock) body in the moment the amount of gas emission.

\section{Effect of Ventilation on Gas}

Air flow from the over-flow and the total pressure (absolute static pressure, pressure and speed and pressure of the sum of) high cross-section to the total pressure of the cross-section, and the total pressure of a cross-section of the size of the pressure is strictly uncertain ${ }^{[5]}$. The total pressure difference across the two cross section called the ventilation pressure, the value is equal to the ventilation resistance.

\section{Effect of Total Pressure Change on Gas Emission}

The influence of the two factors on the gas emission rate of the same coal body is the same, while the gas pressure in the coal body is the same as that of the coal body. Cause gas leakage reasons. General broken coal gas pressure is still $0.2-0.3 \mathrm{MPa}$, coal gas pressure is greater, up to $8 \mathrm{MPa}$ or more. The total pressure of any over-flow section in the mine airflow varies up to $0.007-0.01 \mathrm{MPa}$, which is much less than the gas pressure in the coal or broken coal.

The magnitude of the indirect gas emission depends on the difference between the total air pressure in the accumulated gas site and the total pressure in the surrounding roadway. This difference may be greater than the former, the latter may be greater than the former, there may be two equal, that is, the difference is positive or negative, is constantly changing. Due to the tightly closed goaf or the old lane, the accumulation of gas due to outside air flow, the total pressure drop expansion is limited, coupled with ventilation lane roadway, Point, but each point is small, causing the rise of local space gas is not obvious. When the amount of these small, more than the point of emission, concentrated in the total return airway, there may be a significant increase in gas concentration. However, among the factors that affect the gas emission, the change of the indirect source gas due to the decrease of the total pressure in the wind flow is secondary.

\section{Influence of Air Volume Variation on Gas Emission}

Normal ventilation of the roadway and face, the wind through the coal wall surface gas leakage is constant. But because of wind speed, air flow in a turbulent state, the gas will not be layer. At this point the air carrying the gas on behalf of the coal wall of the gas emission, due to changes in air flow caused by changes in the direct source of gas emission is not obvious.

For indirect sources of gas, air flow changes in the air will cause significant changes in the gas. Such as the mined-out area behind the working face, field and laboratory observations have proved the results. The increase or decrease of the airflow in the working face not only causes the gas quantity carried by the return airflow to increase and decrease correspondingly, but also causes the gas concentration to increase or decrease correspondingly under certain conditions. In this case, if the 
method used to increase the amount of air to solve the backflow of gas concentration overrun problem is often impossible.

The amount of gas or gas concentration increases with the amount of wind phenomenon is time, this time is sometimes short and sometimes short. It is mainly determined by the amount of gas accumulated in the goaf and the amount of gas flowing into the goaf in the adjacent layer, the amount of air leaking into the goaf, and the rock condition in the mined-out area. But because the air volume change is frequent, a change in air volume along with the gas volume or gas concentration has not yet changed when the end, the second air flow changes have emerged, so the performance is the amount of gas with the air flow changes. In short, the air flow changes on the indirect source of gas emission has a significant impact.

\section{Influence of main fan outage on gas flow}

The main fan outage, fan pressure loss, the mine is completely natural wind pressure conditions. At this point the amount of mine gas emission is the total air pressure and wind volume (or wind pressure) the combined effect of the results. Because the natural wind pressure is small relative to the mechanical wind pressure, the air volume (or wind pressure) of each section of the roadway is reduced, and the air flow in a certain section The total pressure is increased. The indirect source gas accumulated in the enclosed space will be reduced due to the decrease of the air volume and the little pressure of air will flow into the closed space due to the increase of the total pressure. The two together will result in the gas emission Reduction.

\section{No pillar mining}

No coal pillar mining area, flowing through the mined-out area of the air leakage and stay coal pillar mining is not the same, so the air leakage on the gas emission has a significant impact. In the case of non-pillar U-type ventilation face, because of the elimination of section pillars, the air leakage in the goaf is not concentrated in the return air corner and becomes dispersed, so the air leakage velocity is reduced. Gob collapse fully, increase air leakage resistance, but also can reduce the width of the main air leakage to reduce air leakage. As a result, the gas carried in the gob is reduced. When the coal seam gas content is high, multi-coal mining, from the adjacent layer of gas emission is also great, and stable emission of time; Gob collapse is not sufficient, the face into the air volume; or only the mining of this layer canceled Coal pillar and the adjacent layer still left pillars; methane drainage effect is not good, there may be no coal pillar mining face or mining area of gas emission is still large. In this regard, should be possible under the conditions, on the one hand to improve the gas drainage rate, reduce air emissions, on the other hand the air leakage or goaf air leakage into the return airway or the total return airway, reduce the working surface or The area of the burden of gas emission, so that gas does not exceed the limit.

\section{conclusion}

On the one hand, coal mining without coal pillar improves the recovery rate of coal, and the decrease of the remaining coal content also has a positive effect on the prevention of spontaneous combustion in goaf. The influence of total gas pressure, air volume variation and main fan stop on gas emission is expounded, and a concrete analysis is made on the non-pillar mining. It is emphasized that air leakage is the main influencing factor of gas emission quantity of the key factors, on-site production has a certain reference value.

\section{References}

[1] Yongxin Xu. Coal Mining Science [M]. Xu Zhou: China University of Mining and Technology Press, 2009, In Chinese. 
[2] Deming Wang. Mine Fires [M]. Xu Zhou: China University of Mining and Technology Press, 2008, In Chinese.

[3] Baoshan Jia, Bin Yin, Lifeng Lin,et,al. Plugging technology applied to fire prevention of mining without coal pillar[J]. Fire Safety Science, 2012, 21(01): 35-39, In Chinese.

[4] Peiliang Ma. Coal Mine Gas Disaster Prevention Technology manual[M]. Bei Jing: Chemical Industry Press, 2007, In Chinese.

[5] Yuanping Hang. Mine Ventilation [M]. Xu Zhou: China University of Mining and Technology Press, 2003, In Chinese. 